\title{
Maritime Design Process Improvement Through a Lean Transformation
}

\author{
Brendan P. Sullivan, Monica Rossi, Lucia Ramundo and Sergio Terzi
}

\begin{abstract}
The maritime industry has been working to apply unique solutions capable of improving design and development performance to ensure competitiveness [1-4]. Over the past several decades, the industry has faced changes related to the increasing complexity of the dynamic global market. Activities to meet these challenges have been carried out in the marine space (e.g. aquaculture, renewable energy, environmental monitoring, accident response and clean up), however, design methodologies have remained rather unchanged, regardless of demand for the incorporation of new technologies and materials. Literature and multiple case studies have been utilized to present a design methodology and its preliminary results, which aim to help transform the design process for the extension of serviceability and reduction of design time. This paper describes an innovative maritime design framework, based on the comprehensive usage of design methodologies and advanced technology integration in vessel design.
\end{abstract}

Keywords Lean design - Maritime design • Collaborative design • Case study • Design methodology

B. P. Sullivan $(\varangle) \cdot$ M. Rossi $~$ L. Ramundo $\cdot$ S. Terzi

Department of Management, Economics and Industrial Engineering, Politecnico di Milano, Via Lambruschini, 4/B, 20156 Milan, MI, Italy

e-mail: brendan.sullivan@polimi.it

M. Rossi

e-mail: monica.rossi@polimi.it

L. Ramundo

e-mail: lucia.ramundo@polimi.it

S. Terzi

e-mail: sergio.terzi@polimi.it 


\section{Introduction}

The maritime industry has throughout history been a vital aspect to economic development, creating wealth and expanding influence through international and interregional trade. The continuing diversification of economies, the flow of knowledge, resources, goods and services have become more vital than ever owed to technological and sociocultural forces [5-7]. These continued advancements require that vessel designers develop new approaches capable of creating value-added services, management, and designs.

Like other industries it has become increasingly important for companies to improve their processes to maintain competitiveness, prosperity, and survival. Recently European maritime industry has been dealing with increased competition, due to ports becoming strategic poles of distribution for maritime traffic to/from new emerging countries. To facilitate and increase the competitiveness of the European maritime sector, lessons learned from the naval and specialized vessel industry have served as a key element in future development. This includes the incorporation of new technologies, materials and optimization processes into the engineering and design practices of the greater industry [7,8]. At the same time, the European Maritime sector must diversify their business offerings and be capable of integrating these advanced technologies into design processes to be competitive in the global market. To date, the industry has been working to implement and apply many of these advancements in their engineering and development processes [2]. However further work remains beyond application alone to identify and develop value-added solutions, products and services that can accommodate changing demands in the sector.

In order to address the challenge of implementing lean in maritime design, both academic literature and industrial feedback are utilized to reduce the challenge of implementing lean for designer and engineers during the conceptual, preliminary, contract and detailed vessel design phases. This paper introduces a unique lean method for process improvement that was developed alongside industry partners for Small-Medium-Enterprises (SMEs), to leverage technological solutions and overcome barriers that inhibit the implementation of lean, such as: (1) the isolated implementation of lean tools in design processes, (2) the articulation of requirements for specialty and one-of-a-kind vessels between designers and stakeholders, and (3) overcoming entrenched habits amongst vessel designers.

\section{Lean}

The original definition of lean thinking aims at "creating more value, defined from the customer's perspective, while consuming fewer resources" [9]. Since emerging in the early 1990s from the Japanese automotive sector, leans ability to facilitate 
improvement in project management, simultaneous development, teamwork, and communication has made it well suited for applications in design and development.

Since its introduction, lean has evolved into an approach that considers entire enterprises with emphasis on organizational behavior, work flow, design, and production processes through continual improvement. Expanding from the traditional production sectors, to industries involved in advanced and complex design and development processes such as the space industry (JPL, Team-X and ESA) [10-12]. However, the possibility to improve the overall performance of complex system development through the proper adoption of best practices and innovative methods has been identified as critical area for several sectors including maritime.

\subsection{Lean Product Development}

Lean Product Development (LPD) is the application of lean thinking and principles to product development (PD) projects, in an attempt to support companies willing to implement lean thinking, tools and techniques to improve the overall performance of their processes [9, 13-15]. Through emphasis on waste reduction and process improvement Lean has successfully demonstrated that when considered in earlystage decisions, lifecycle value and product performance (quality, reliability, safety, etc.) are improved.

In recognizing the dispersion of the concept, when being applied to PD several considerations must be understood. First, PD is different from a repetitive production process, in that the former has information as its main input and output, while the latter mainly deals with materials $[15,16]$. Second, PD is characterized by a higher level of variability and uncertainty compared to the production process of largescale manufacturing companies and this could prevent an effective delivery of value and identification of "wastes" [17]. As such this consideration is critical for the management of projects, where the complexity of the system being developed is high and cost as well as delivery time are critical [18-20]. The literature showed that in cases of successful LPD implementation there are at least three important advantages provided that include a/an:

- Improved development performance [21, 22].

- Improved efficiency in manufacturing and processes [21].

- Structure for establishing a lean enterprise [9, 23].

\subsection{Lean Product and Process Development}

Lean Product and Process Development (Lean PPD) considers the design and development of engineering products to facilitate the integration of manufacturing knowledge during the conceptual design stage to increase designer awareness of manufacturing constraints and manufacturing capabilities $[24,25]$. To prevent diminished 
value, it is necessary to analyze and specify requirements with the stakeholders at the very beginning of the project, thereby allowing for rapid alternative generation. In considering the flow of information, it is necessary for strong coordination so that interrelated information flows can be brought together. This allows for the transfer of knowledge in a harmonic manner, whereby analysis, simulation, prototypes, and test information are available to not only those performing them, but all who are involved in the design process.

Similarly, lean design is the application of lean tools and principles, for the elimination waste and non-value added activities in design related processes [26]. In application, this approach aims to fulfil stakeholder needs through the exploration of alternatives to determine how requirements can most effectively be accommodated to deliver the highest level of value. Through the consideration of design alterations, information flow, and value generation, lean reduces waste by minimizing the amount of time before information gets used, the time spent inspecting information for conformance to requirements, the time spent reworking information to achieve conformance, and the time spent moving information from one design contributor to the next $[27,28]$. The difference in these considerations is how the process describes the critical design aspects and properties.

\section{Maritime Design}

Vessels are inherently complex one-of-a-kind products that are built by highly skilled persons according to specific requirements set by the stakeholders and many times require unique solutions that are drawn upon from previous or existing designs [29, 30]. This practice allows for a designs process that is quick and straight forward to apply. Managing the specific requirements, stakeholder interests (builders, cargo owners, customers, ports operators, classification societies, environmental matters, comfort of the crew/passengers, etc.), optimization criteria and technical feasibility. In addition when designing a "standard" vessel, this approach reduces the risk for failure and ease for verifying compliance to national and international legal regulations [31, 32]. Despite the obvious benefits presented by this approach, it can be difficult to incorporate new innovative solutions due to the restrictiveness of the design space [33].

\subsection{Lean in the Maritime Industry}

In the maritime industry lean is a growing area within engineering and manufacturing of maritime vessels due to cost, size and complexity. As in many industries, vessel design has many Non-Value-Added Activities (referred throughout this deliverable as WASTE or "MUDA") which increase costs, compromises quality and can propagate delays in the delivery schedule, which all in effect provide no positive contribution 
for the stakeholders. With origins of the concept generally contributed to Japanese shipyards which reached peak profitability and competitiveness far before the more well-known auto industry [1,34]. Despite this the number of publications on lean are limited, with few published cases that utilize lean principles in an organized manner during design. This can be contributed to the novelty and the general restrictive nature of the concept, particularly related to the processes of organization being used in each yard [35].

Lean construction/shipbuilding is one of the more researched areas of lean in relation to the maritime industry, representing an adaptation of lean manufacturing principles and practices to construction and shipbuilding through advanced focus on planning. It is critical to note that these approaches and principles are not learned from the Japanese ship industry which as stated by Koenig could have served as the initial knowledge flow of lean in the industry [1].

Shipbuilding can therefore be viewed as a process that extends beyond the typical design phases, incorporating the requirements selection, stakeholder interests (builders, cargo owners, customers, ports operators, classification societies, environmental matters, comfort of the crew/passengers, etc.), optimization criteria and technical feasibility. The increased phases of construction mean it is necessary for design information to be well organized and defined so labor and materials can establish to reduce inventories. According to the description of the concept, lean construction tries to manage and improve shipbuilding through advanced planning, and emphasis on concurrent/continuous improvements throughout the entire systems life $[30,35,36]$.

\section{Research Approach}

The research covered in this paper utilized a systems development approach due to its ability to facilitate a close examination of the lean design process in the maritime industry and specific lean tool implications. Whereby product design literature was applied to develop a comprehensive methodological foundation that included elements of lean systems engineering, and lean design. The System Development Methodology is classified as an applied method that allows for planning, creating and testing of systems through an integrated multi-methodological research approach (Fig. 1). Theory Building is the central tenant of this process and aims to improve the practical understanding of a problem space.

Through the identification of existing practices as well as the incorporation of best practices identified through literature, a methodology was constructed based on the unique needs of the maritime cases. 


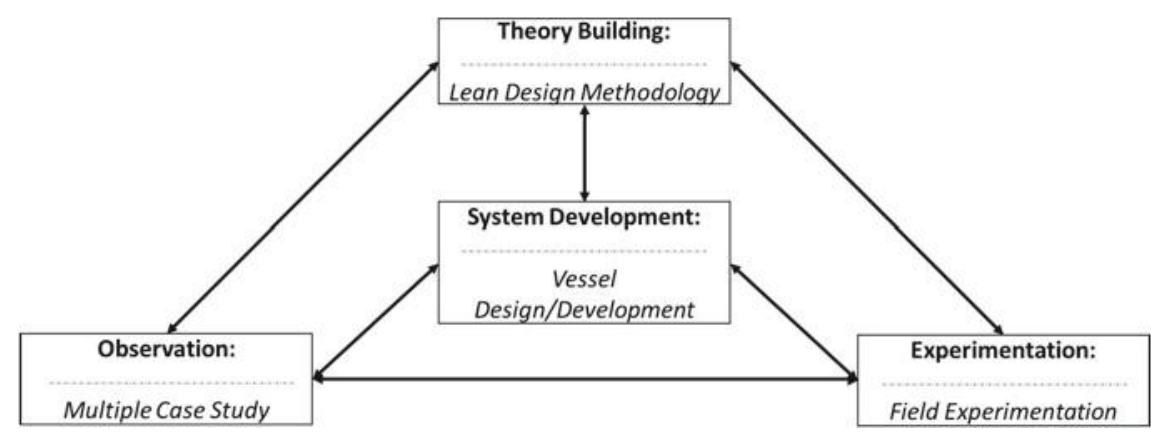

Fig. 1 Approach for system development [37]

\subsection{Research Design}

The research presented draws upon the findings of multiple case studies conducted in collaboration with three vessel producers due to its ability to provide for an in-depth investigation and ability to leverage different data collection techniques to provide a comprehensive overview of the problem under investigation. In order to acquire relevant and quality data to test the research hypothesis it was necessary for the project size and sea related sector and offshore and coastal activities of the vessels to be similar as shown in Table 1 [38]. Further, the business type and production approach were specified, while design process similarity was desired the cases were not selected based on this criterion.

\section{Case in Maritime Design}

Most shipyards and those involved in vessel design (managers, designers, engineers) are acutely aware of the need for innovations and continuous development. Frequent product introductions, upgrades, facelifts etc. are always on top of the agenda for shipyards and the maritime industry respectively. Even though some level of standardization has been achieved, the level of customization is high compared to other branches such as automotive. This makes design and production processes difficult to manage since every vessels typically requires new and unique solutions.

Table 1 Business case characteristics

\begin{tabular}{l|l|l}
\hline Case & Business & Vessel classification \\
\hline$\# 1$ & SME & MCA CAT $2(>60$ nautical miles from safe haven $)$ \\
\hline$\# 2$ & SME & MCA CAT $2(>60$ nautical miles from safe haven $)$ \\
\hline$\# 3$ & SME & MCA CAT $3(>20$ nautical miles from safe haven $)$ \\
\hline
\end{tabular}


Table 2 Maritime design process maturity

\begin{tabular}{|c|c|c|c|}
\hline Case & Organization & Process & $\begin{array}{l}\text { Knowledge } \\
\text { management }\end{array}$ \\
\hline$\# 1$ & $\begin{array}{l}\text { (Mature) } \\
67.8 \%\end{array}$ & $\begin{array}{l}\text { (Intermediate) } \\
58.9 \%\end{array}$ & $\begin{array}{l}\text { (Intermediate) } \\
55.7 \%\end{array}$ \\
\hline$\# 2$ & $\begin{array}{l}\text { (Mature) } \\
74.3 \%\end{array}$ & $\begin{array}{l}\text { (Mature) } \\
65.3 \%\end{array}$ & $\begin{array}{l}\text { (Mature) } \\
75.7 \%\end{array}$ \\
\hline$\# 3$ & $\begin{array}{l}\text { (Mature) } \\
69.8 \%\end{array}$ & $\begin{array}{l}\text { (Intermediate) } \\
56.1 \%\end{array}$ & $\begin{array}{l}\text { (Intermediate) } \\
55.2 \%\end{array}$ \\
\hline Average & $\begin{array}{l}\text { (Mature) } \\
70.6 \%\end{array}$ & $\begin{array}{l}\text { (Intermediate) } \\
60.1 \%\end{array}$ & $\begin{array}{l}\text { (Mature) } \\
62.2 \%\end{array}$ \\
\hline
\end{tabular}

\subsection{Design Process Maturity Analysis}

Interviews were conducted using a reference questionnaire, comprised of 33 questions identified through literature and best practices. In each case, the technical director was interviewed, lasting roughly $3 \mathrm{~h}$. The questions were scored using a Likert scale, so the respondent could choose their company's process level. The lowest levels scored with 1 correspond to a poor practice, while the highest-level scored correspond to a best practice. The score for each area was calculated using an additive scale (summing the single scores of the questions describing the area) then normalized in \% [39].

Based on the maturity level established by the CLIMB assessment method, efficacy of the practice was calculated as being either: Chaos (0-20), Low 24-40\%, Intermediate 41-60\%), Mature (61-80\%), or Best Practice (81-100\%) [39, 40].

- Organization: how people are involved in daily activities: coordination of people and activities, roles of engineers and designers, skills/expertise of practitioners.

- Process: how vessels are developed, based on four areas: design rules (Methods), control mechanisms (Process Management), how decisions are made (Decision Making), and competitors and customers involvement (Activities and Value).

- Knowledge Management: how the case creates, shares, represents and re-uses knowledge. Including how knowledge is formalized, shared and integrated into the design process.

The design process maturity in each case (Table 2) illustrates that in each case while scoring relatively high there are still obvious deficiencies, particularly relating to: Process and Knowledge Management which have the lower average score.

\subsection{Waste Analysis}

Improper or incomplete designs are one of the biggest causes of waste due to the negative effect these design failures can have during later stages [15]. For this reason, 
it was important early on to determine the types of waste present in maritime design. To do this, activities that failed to generate value were categorized in three ways: (1) Waste of Time (WoT), (2) Waste of Knowledge (WoK), or (3) Waste of Resources (WoR). According to this classification 10 wastes of a possible 33 proposed by Rossi et al. [13] were selected to be measured, as shown in Table 3.

The identified wastes were measured in each case through the waste identification method developed by Rossi et al. [13], and is based on the FMEA (Failure Modes and Effects Analysis). Through this approach 5 engineers/designers in each business were asked to evaluate the Probability (P), Severity (S), Detectability (D), and Avoidability (A) of the afore mentioned wastes in their design processes.

Post waste evaluation of the Priority Index of Intervention $(\mathrm{P} * \mathrm{~S} * \mathrm{D} * \mathrm{~A}=\mathrm{PII})$ for each waste was calculated individually, and the average PII was calculated. In the following histograms the average PII value for each waste is presented (Fig. 2Left) and the average PII value of each waste class (Fig. 2-Right), the height of the bar (y axis) corresponds to the value of PII and the $\mathrm{x}$ axis the waste or class being measured. The black line on (Fig. 2-Right) compare the average SME waste value in traditional industries against those in design [13].

Table 3 Business case characteristics [13]

\begin{tabular}{l|l}
\hline Waste & Description \\
\hline \#1 Change priorities & Time making changes, reviews, modifications or reworks \\
\hline \#2 Reworks & $\begin{array}{l}\text { Projects (of parts of projects) re-done due to incorrect, incomplete, } \\
\text { unreliable data, information, specifications }\end{array}$ \\
\hline \#3 Unneeded functions & Functionalities and features that are not necessary or required \\
\hline \#5 Project leftovers & Projects are realized that never reach the market \\
\hline \#6 Data transcoding & Information and data are inserted and coded manually \\
\hline \#7 Missing authorization & Projects are delayed due to authorizations challenges \\
\hline \#9 No knowledge reuse & $\begin{array}{l}\text { Projects, developed in the past, are redone due to previous } \\
\text { knowledge not being retrieved }\end{array}$ \\
\hline \#10 Over engineered & Over-engineering; cost increase without value added \\
\hline
\end{tabular}
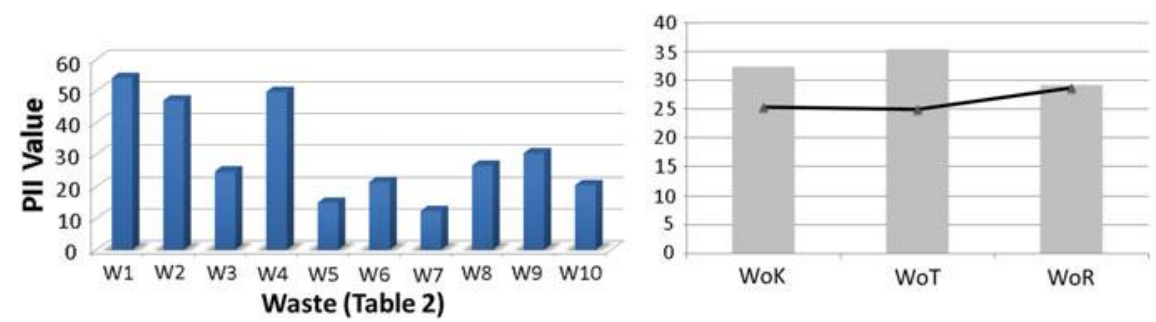

Fig. 2 Waste PII in maritime design 


\subsection{Barriers to Lean Implementation}

Based on the process maturity and wastes identified it has been determined that there is a relationship between how mature a process is and how present a waste is. Amongst the maritime cases analyzed it is therefore necessary for the methodology supporting lean transformation to be able to consider and address multiple areas of the organization simultaneously, particularly through the better leveraging of knowledge and improvement on processes to reduce changes [41]. Through the analyses performed and interviews conducted three distinct barriers to lean implementation were identified: (1) the isolated implementation of lean tools in design processes, (2) the articulation of requirements for specialty and one-of-a-kind production (OKP) vessels between designers and stakeholders, and (3) overcoming entrenched habits amongst vessel designers.

The first barrier represents within the maritime industry a general lack of methodologies capable of support the integration and implementation of lean into the design process. In each case, it was found that at some point over the past 5-years an effort had been undertaken to implement lean or a lean tool. In each case the effort was ultimately abandoned and attributed to there being little to no cohesion between multiple lean efforts, and the inability to train each person involved how best to leverage the capabilities of the tool. This is potentially caused by the limited number of solutions that consider the integration of supporting tools according to the unique needs of specific industries or organizations.

This general lack of how to integrate lean into one's process is further explained in the difficulty of articulating requirements for on-of-a-kind vessels where changes in customer requirements lead to the recreation of designs, drawings and documentation. In discussions surrounding past projects there are instances where the customer is paying for the convenience to change their mind at any point during development. While this ability to satisfy customer expectations is valuable, the output should be able to be generated in the most efficient manner possible. All improvements relating to value require that there be some action taken towards the associated cost or the function, so that requisites can be transmitted effectively and, in a value, positive manner.

In discussing the third barrier, which is overcoming extant habits it is understood that the maritime industry is risk averse, as careful considerations are always made to ensure the safety and reliability of vessels. Despite the obvious benefits presented by this, it can be difficult to incorporate new innovative solutions due to the restrictiveness of the design space and the entrenched educational aspects that have been taught. This third barrier could in part explain why in review of the available literature there very little information is available for integrating lean, and methods to facilitate a lean transformation. 


\section{Design Process Improvement Through Lean Transformation}

The maritime industry is one of the most recent industries that has been working to apply unique solutions capable of improving their development performances. However, based on the cases covered in this paper there is not only a need to overcome the identified barriers, but also provide an approach that overcomes the principles wastes and would facilitate process maturity. For this to be realized the lean transformation of the design process must have a wider scope than previous lean efforts and involve all levels of the organization. This comprehensive approach is necessary due to there being a critical distinction between mass production and OKP, as is the case in many vessel design efforts.

Considering this in the development of the methodology it was determined to be necessary to draw a distinction between the creation of a methodology that dictates the technical procedures/considerations for vessel design and the managing process of the design that describes how tools and approaches should be chosen to successfully implement lean. In addressing the latter, this Lean Transformation Framework (LTF) is presented to combat delays and barriers being faced when implementing lean in vessel design.

Like product development which deals with information and processes, involving a multitude of choices and iterations that are used for problem solving and decisionmaking activities [42]. The maritime industry is confronted with the management of iterations and complex development, the LTF aims at improving development performances by promoting a stronger relationship between the designer and customer, and by facilitating an improved approach for utilization of past designs and vessel data [43]. To facilitate the optimization of this initiative, an evaluation of diffused strategies was undertaken.

Through a holistic question-based approach the methodology offers a customizable set of tasks and steps that can be easily modified to facilitate implementation of lean in various maritime design process or organizations.

- What problem is trying to be solved?

- What is the value for the stakeholder?

- How can the organization improve to better deliver the identified value?

- What skills, attributes, or characteristics are necessary to engage in these processes to best deliver value to the stakeholder?

- Is the current management system capable of supporting this way of working, and what management system is?

- What considerations and values/goals will be used to guide the lean transformation of the organization? The set of foundational things such as how to carry oneself, "attitude". 


\subsection{Lean Transformation Facets}

The LTF focuses on value creation through the elimination of non-value adding activities through the identification and implementation of tools that are well suited to vessel design. Therefore, one should identify first the right customer value the product should fulfil. Further, any activities that add no value for the customer should be identified and eliminated from the process.

\subsubsection{Purpose}

In considering ways to address 'Purpose' there are several tools and approaches, which have been identified in the state of art and practice could be included. One such approach that is well suited to meet this area based on a review of the literature is the improvement of customer involvement in the design process, this relates to the identification customer requirements through increased user involvement.

User involvement allows for the identification and accurate definition of system requirements to maximize value. Clear calculation of the 'purpose' addresses customer needs and attributes of the stakeholders regarding the product/system, by articulating what the customer wants to have in the vessel and the functions they want it to perform in a specific environment. Needs in this context are a wish list based on the expectations that stakeholders have for the system. In determining and considering this list, it is critical to recognize that a wide range of stakeholders can affect the product development process, a successful design must consider all those stakeholders involved: designers, engineers, shipyards and suppliers. Through greater customer involvement the following approaches were found to be well suited for cost-minimization, and increased design efficiency.

- Requirement Engineering.

- Customer Value Integration and Definition.

Recognizing that the maritime development process is a sequence of steps and activities that are employed to conceive, design, and successfully deploy a vessel. To succeed in these efforts, designs must maximize customer value, while ensuring careful conformity to regulations and safety concerns.

\subsection{Process}

'Process' is the manner in how work can be done and organized to fulfil desired goals and objectives related to the delivery of value for the customer. Referring not only to how a process should be performed, but also how the work can be continuously improved. This includes implementing: 
- Set-Based-Concurrent-Engineering or Concurrent Engineering.

- Knowledge Based Engineering.

- DfX.

Each implementable process must fulfil the overarching business needs and is intended to promote efficiency without creating or establishing non-value (wasteful) efforts, allowing for the use of fewer/less resources. These approaches when integrated in the design process can be adapted for to ensure customer needs are met and allow for the integration of user data for future improvement.

\subsection{People}

In considering ways to address 'People' it is critical for the purpose and process of the transformation to be well understood by all employees. This verifies that the necessary skills, and attributes, can be offered during every stage of design process so that designers and engineers have the appropriate and necessary skills to tackle problems effectively utilizing product usage information and experience to generate and evaluate alternative design concepts in a collaborative and efficient manner.

- Skill Training and Engagement.

- Knowledge Sharing.

Through training and knowledge sharing in the vessel design process communication facilitates a pull event where teams can visualize risk and opportunities to improve and enhance design efforts. 'Serious Games' have also been identified as a successful approach, which allows players to assume different roles and engage them in simple and complicated decision-making processes. This process of gamification also makes it possible for a safe and entertaining environment to be established, where players are openly encouraged to investigate processes without fear of interfering in actual design.

\subsection{Basic Thinking}

Basic thinking considers the values/goals that will be used to guide the lean transformation of the organization. Based on the business needs value delivery efforts, it is possible to continually improve the design and development process, in a sustainable and environmentally responsible manner [44]. In considering the values/goals that can be used to guide the lean transformation of the following approaches were identified:

- 5-step methodology for continuous improvement.

- Fostering an Innovative Culture. 
These approaches serve to integrate all parts of the transformation and facilitate the improvement of the design process (no matter if it is lean or not) through a lean perspective.

\subsection{Leadership and Management}

The leadership aspect represents the fifth part of the transformation and represents the soft skills, behaviors and tools to be utilized by leaders and everyone within the organization so that they can meet the objectives of the process improvement effort in an effective and collaborative manner. It has been found that the way peoples engage and interact with one another directly impacts the amount of respect, empowerment, and support in the organization. In involving people, the leadership can directly increase employee-driven participation (strongly related to Fostering an Innovative Culture).

In pursuing these aims every program/project (the entire transformation and smaller projects) should use a Chief Engineer role to lead and integrate the program from start to finish. Through the utilization of a chief engineer, leaders are responsible for defining, translating and communicating the purpose, strategy and goals throughout the organization to everyone, ensuring that a clearly crafted message is developed. Which provides flexibility for those involved to determine how to best accomplish and measure them. Failure to provide such a collaborative approach has limited efficacy and staying power if the right people are not supported at the right time.

\section{Concluding Remarks and Future Work}

This paper which part of a greater combined research effort is representing preliminary and ongoing work, aiming to introduce a lean transformation methodology that is and easily implementable in the maritime industry and through a series of questions can be tailored to unique needs while overcoming barriers that challenge lean implementation in vessel design. Through the implementation of the LTF for design process improvement it is expected that designers and engineers will have a more comprehensive view of the design, in order to reduce wastes in the process.

This methodology seeks to extend the advantages of lean to a new area of the industry to improve the value of SME vessel offerings. Emphasizing the objective of reducing design time through the reduction of the most significant wastes measured during the observation phase of this research we sought to improve employee skills and increase the synchronicity of processes. The current state of the implementation has demonstrated strong potential with sea trials in two cases underway. While work is ongoing, several benefits have been detected, specifically a faster pace for design variations of vessels, and the diffusion of skills and knowledge to support efforts. 
However, there are further refinements and details expected to be made for the method to be suitable for the greater Maritime Sector. This will involve testing to verify its efficacy and ability to be applied to the design of different vessel types. Additional studies will be needed to understand if the use of the methodology and best practices are context dependent. Additional data related to the value (benefit) of unique lean tools is being collected and will then begin to integrate new sensor data into the design processes for each vessel. The KPI data has not yet been reported. Through complete implementation in the three cases (from concept design to vessel delivery) the methodology will be validated to confirm the objectives set forth in the project. This will allow for the ultimate determination if the methodology needs to be adjusted to better serve the purpose of supporting such a challenging industry.

Acknowledgements The content of this paper is based on the LINCOLN project (EU H2020 727982) that is currently under development (www.lincolnproject.eu). We wish to express our deep gratitude to all LINCOLN partners.

\section{References}

1. Koenig PC, Narita H, Baba K (2002) Lean production in the Japanese shipbuilding industry? J Ship Prod 18(3):167-174

2. Milanovic V (2016) Application of set-based concurrent engineering to shipbuilding projects. MS Engineering and ICT. Norwegian University of Science and Technology

3. Liker J, Lamb T (2001) Lean Shipbuilding. In: Ship Production Symposium, Ypsilanti, MI

4. Radovic I, Macclaren BJ (2004) Lean six sigma in shipbuilding. In: European shipbuilding and repair conference, London, 2 November 2004

5. Corbett JJ, Winebrake J (2008) The impacts of globalisation on international maritime transport activity. In: Global forum on transport and environment in a globalising world

6. Markit IHS (2016) Five trends shaping the global maritime industry

7. Thanopoulou H, Strandenes SP (2017) A theoretical framework for analysing long-term uncertainty in shipping. Case Stud Transp Policy 5(2)

8. Luglietti R, Wurst S, Sassanelli C, Terzi S, Martín CM (2018) Towards the definition of specialized vessels' model. In: 2018 IEEE international conference on engineering, technology and innovation (ICE/ITMC)

9. Womack JP, Jones DT (1996) Lean thinking: banish waste and create wealth in your corporation. Simon \& Schuster, New York

10. Whalen M (2014) Low cost, big return. JPL - Universe, Pasadena

11. León HCM, Farris JA (2011) Lean product development research: current state and future directions. EMJ Eng Manag J 23(1):29-51

12. Welo T (2011) On the application of lean principles in product development: a commentary on models and practices. Int J Prod Dev 13(4):316

13. Rossi M et al (2011) Proposal of a method to systematically identify wastes in new product development process. In: 2011 17th international conference on concurrent enterprising, (Ice), pp 1-9

14. Oehmen J, Rebentisch E (2010) Waste in lean product development. Lean.Mit.Edu 19(1): 471-473

15. Morgan JM, Liker JK (2006) The Toyota product development system: integrating people, process and technology, vol 24 
16. Krishnan V, Ulrich KT (2001) Product development decisions: a review of the literature. Manage Sci. 47(1):1-21

17. Browning TR (2003) On customer value and improvement in product development processes. Syst Eng 6(1):49-61

18. Rebentisch E, Rhodes DH, Murman E (2004) Lean systems engineering: research initiatives in support of a new paradigm. Syst Eng 4(1)

19. Chase JP (2001) Value creation in the product development process. M.Sc. thesis, pp 1-133

20. Oppenheim BW (2011) Lean enablers for system engineering. Syst Eng 14(3):305-326

21. Liker JK, Morgan J (2011) Lean product development as a system: a case study of body and stamping development at ford. EMJ Eng Manag J 23(1):16-28

22. Rossi M, Morgan J, Shook J (2017) Lean product and process development. In: The Routledge companion to lean management

23. Garcia P, Drogosz J (2007) Lean engineering - best practice in the automotive industry. SAE Tech Pap

24. Khan $\mathrm{M}$ et al (2013) Towards lean product and process development. Int J Comput Integr Manuf 26(12):1105-1116

25. Kerga E, Taisch M, Terzi S, Bessega W, Rosso A (2014) Set-based concurrent engineering innovation roadmap (SBCE IR): a case on adiabatic humidification system. Int J Des Creativity Innovation 2(4):224-255

26. Mascitelli R (2004) The lean design guidebook: everything your product development team needs to slash manufacturing cost

27. Oppenheim BW (2004) Lean product development flow. Syst Eng 7(4):352-376

28. Browning TR et al (2002) Adding value in product development by creating information and reducing risk. IEEE Trans Eng Manag 49(4):443-458

29. Longva KK (2009) Warehouse management in a lean shipbuilding perspective-an exploratory case study of Ulstein Verft. Høgskolen Molde

30. Salem O, Solomon J, Genaidy A, Minkarah I (2006) Lean construction: from theory to implementation. J Manag Eng 22(4)

31. Hamann R, Peschmann J (2013) Goal-based standards and risk-based design. Sh Technol Res 60(2):46-56

32. Molland AF (2008) The maritime engineering reference book, 1st edn. Butterworth-Heinemann

33. Papanikolaou A (2009) Risk-based ship design: methods, tools and applications. Springer

34. Liker JK, Lamb T (2002) What is lean ship construction and repair. J Sh Prod 18(3):121-142

35. Phogat S (2013) An introduction to applicability of lean shipbuilding. Int J Latest Res Sci Technol 2(6):85-89

36. Dugnas K, Oterhals O (2008) State-of-the-art shipbuilding: towards unique and integrated lean production systems. In: Proceedings of IGLC16: 16th annual conference of the international group for lean construction, 6411, pp 321-331

37. Nunamaker J, Chen M, Purdin T (1991) Systems development in Information systems research. J Manag Inf Syst 7:89-106

38. DG for Maritime Affairs and Fisheries (2009) The role of maritime clusters and development executive summary ECO

39. Rossi M, Terzi S (2017) CLIMB: maturity assessment model for design and engineering processes. Int J Prod Lifecycle Manag 10(1)

40. Rossi M, Terzi S, Taisch M (2014) Engineering and design best practices in new product development: an empirical research. Procedia CIRP 21:2.

41. Nonaka I (1994) A dynamic theory of organizational knowledge creation. Organ Sci 5(1)

42. Shook J (2018) The lean transformation framework. The Lean Enterprise Institute. https:// www.lean.org/WhatsLean/TransformationFramework.cfm

43. Sullivan BP, Rossi M, Terzi S (2018) A customizable lean design methodology for maritime. In: 5th IFIP WG 5.1 international conference, Turin, Italy. https://doi.org/0.1007/978-3-03001614-2 47

44. Rossi M, Taisch M, Terzi S (2012) Lean product development: a five-steps methodology for continuous improvement. In: 2012 18th international conference on engineering, technology and innovation, ICE 2012 — conference proceedings. https://doi.org/10.1109/ICE.2012.6297704 